\title{
Immunohistochemical Detection of Toll-Like Receptor-2, -4 and -9 in Exocrine Glands Associated with Rat Alimentary Tract
}

\author{
Youhei MANTANI ${ }^{1}$, Yuh YOKOO $^{1)}$, Aosa KAMEZAKI ${ }^{1)}$, Kankanam Gamage Sanath UDAYANGA ${ }^{1)}$, \\ Ei-ichirou TAKAHARA ${ }^{1)}$, Takashi TAKEUCHI ${ }^{2}$, Junichi KAWANO ${ }^{1)}$, Toshifumi YOKOYAMA ${ }^{1)}$, Nobuhiko HOSHI ${ }^{1)}$ \\ and Hiroshi KITAGAWA ${ }^{1)^{*}}$ \\ 1)Department of Bioresource Science, Graduate School of Agricultural Science, Kobe University, 1-1 Rokkodai-cho, Nada-ku, Kobe, \\ Hyogo 657-8501, Japan \\ ${ }^{2)}$ Department of Veterinary Laboratory Animal Science, Faculty of Agriculture, Tottori University, 4-101 Koyama-cho Minami, Tottori, \\ Tottori 680-8553, Japan
}

(Received 2 April 2012/Accepted 5 June 2012/Published online in J-STAGE 19 June 2012)

\begin{abstract}
Localization of Toll-like receptors (TLRs) in the exocrine glands associated with the rat alimentary tract was immunohistochemically studied using anti-TLR antibodies. TLR-2, -4 and -9 were detected in the secretory granules of acinar cells or the luminal substances of the gustatory gland, extraorbital lacrimal gland, Harderian gland, proper gastric gland and pancreas. TLR-2 and -9 were also detected in the mucous acinar cells of the sublingual gland. Positivity for all TLRs was found in the striated borders of columnar epithelial cells and the luminal substances of the intestinal crypts throughout the small intestine, and also in the goblet cells throughout the large intestine. Only TLR-4 was detected in the secretory granules of Paneth cells. A reduction of TLR-4-positive secretory granules and the formation of TLR-4-positive vacuoles were found in the ileal Paneth cells under the hyper-proliferation of indigenous bacteria. In the apical to middle intervillous portions of the ileum, Gram-positive bacterial colonies were significantly more abundant than Gram-negative bacterial colonies, whereas this difference disappeared in the basal intervillous portions. These findings suggest that there are distribution differences in the secretory sources of soluble TLRs that possibly neutralize their luminal ligands, in the rat alimentary tract. Therefore, the bacterial ligand-recognition system composed of the membranous TLRs of villous columnar epithelial cells and soluble TLRs from crypt epithelial cells might contribute to host defense mechanisms for the selective elimination of Gram-positive bacteria rather than Gram-negative bacteria in the rat small intestine.

KEY WORDS: alimentary tract, exocrine glands, immunohistochemistry, rat, soluble Toll-like receptors.
\end{abstract}

doi: 10.1292/jvms.12-0146; J. Vet. Med. Sci. 74(11): 1429-1438, 2012

In the animal alimentary tract, a large number of indigenous bacteria settle and make a symbiotic relationship with their hosts. The intestinal microflora has beneficial effects for their hosts, such as the competitive exclusion of potentially pathogenic organisms and production of nutrients, like short fatty acids and vitamins [3, 32]. On the other hand, indigenous bacteria can also have detrimental effects, including competing for calories and essential nutrients, and opportunistic infections [3, 4]. Bacterial colonization in the gastrointestinal tract initiates immediately after birth, and the composition and number of indigenous bacteria are almost stable under physiological conditions in adults [6]. The fundamental settlement sites of indigenous bacteria are the surfaces of the most luminal portions of mucosa throughout the rat alimentary tract $[10,19,20,38,39]$. Indigenous bacteria proliferate from the apical portions of the intestinal villi into the intervillous spaces in the rat small intestine [38]. The proliferation of indigenous bacteria in the intervillous spaces leads to various host responses, such as the reduction of villous height, the acceleration of the

\footnotetext{
*Correspondence to: Kitagawa, H., Laboratory of Histophysiology, Graduate School of Agricultural Science, Kobe University, 1-1 Rokkodai-cho, Nada-ku, Kobe, Hyogo 657-8501, Japan.

e-mail: hkitagaw@kobe-u.ac.jp

(C)2012 The Japanese Society of Veterinary Science
}

epithelial cell migration [31], and the transient secretion of lysozyme and soluble phospholipase A2 (sPLA2) from Paneth cells [40, 41]. From these findings, it has been speculated that special membrane receptors for the detection of indigenous bacterial proliferation exist on the surfaces of the intestinal villi in the rat small intestine.

Toll-like receptors (TLRs) recognize bacterial components: TLR-2 recognizes peptidoglycan, lipoproteins and lipoteichoic acids contained in the bacterial cell wall, TLR-4 recognizes lipopolysaccharides (LPS) contained in the cell wall of Gram-negative bacteria, and TLR-9 recognizes non-methylated $\mathrm{CpG}$ motifs abundantly contained in bacterial DNA [1, 16, 30]. In the previous study, we detected TLR-2 in the striated borders of the villous columnar epithelial cells throughout the rat small intestine, and also TLR-4 and -9 in the striated borders of the villous columnar epithelial cells only in the rat duodenum [26]. However, it is still unknown how host cells recognize the bacterial proliferation in spite of the release of a large amount of TLRs ligands from numerous indigenous bacteria in the chyme.

Recently, soluble TLRs (sTLRs) have been detected in various secretions, such as human saliva, breast milk or blood plasma [24, 25, 34, 45]. sTLRs in blood plasma are speculated to be derived from monocytes or macrophages, because sTLR- 2 and -4 have been shown to be secreted 
into the culture supernatant by freshly isolated human monocytes or a mouse macrophage cell line [21, 25]. sTLRs are detected in various exocrine glands, such as the parotid gland, lacrimal gland and gland of the uterine cervix using immunohistochemistry or RT-PCR methods [5, 14, 24]. However, the entire spectrum of sTLRs secretion sites in the animal alimentary tract has never been clarified. Therefore, this study aims to determine the secretion sites of sTLRs against bacterial ligands using an immunohistochemical method, and also to discuss the possible functions of sTLRs in the rat alimentary tract.

\section{MATERIALS AND METHODS}

Animals: Ten male Wistar rats aged 7 weeks (Japan SLC Inc., Hamamatsu, Japan) were maintained under conventional laboratory housing conditions. They were permitted free access to water and food (Lab MR Stock, Nosan Corp., Yokohama, Japan). The animal facility was maintained under conditions of a $12 \mathrm{hr}$ light/dark cycle at $23 \pm 1^{\circ} \mathrm{C}$ and $50-60 \%$ humidity. Clinical and pathological examinations in all animals confirmed no signs of disorder. This experiment was approved by the Institutional Animal Care and Use Committee (Permission number: 22-05-01) and carried out according to the Kobe University Animal Experimentation Regulations.

Tissue preparation: For immunohistochemistry, 5 rats were intravascularly perfused with $4 \%$ paraformaldehyde fixative (4\% PFA; pH 7.4) after euthanasia with overdose peritoneal injection of pentobarbital sodium (Kyoritsu Seiyaku, Tokyo, Japan). After perfusion, small tissue blocks were removed from the parotid gland, submandibular gland, sublingual gland, extraorbital lacrimal gland, Hardarien gland, tongue, glandular part of stomach, pancreas, liver, duodenum, jejunum, ileum, cecum, ascending colon, descending colon and rectum. The tissue blocks were immersion-fixed in cold $4 \%$ PFA for $6 \mathrm{hr}$ at $4^{\circ} \mathrm{C}$, and were snap-frozen in liquid nitrogen with reference to the embedding method described by Barthel and Raymond [2]. Sections $4 \mu \mathrm{m}$ in thickness were cut using a Coldtome HM505E (Carl Zeiss, Jena, Thüringen, Germany), placed on slide glasses pre-coated with $0.2 \%$ 3-aminopropyltriethoxysilane (Shin-Etsu Chemical Co., Tokyo, Japan) and stored at $-20^{\circ} \mathrm{C}$ until use.

For Gram's stain, the other 5 rats were intravascularly perfused with 4\% PFA after euthanasia with an overdose peritoneal injection of pentobarbital sodium (Kyoritsu Seiyaku). After perfusion, small tissue blocks were removed from the ileum. Then, the tissue blocks were immersion-fixed in cold $4 \%$ PFA for $6 \mathrm{hr}$ at $4^{\circ} \mathrm{C}$, dehydrated and embedded in paraffin with routine methods. Sections $4 \mu \mathrm{m}$ in thickness were cut along the longitudinal axis of the canal. They were mounted onto slide glasses pre-coated with $0.2 \%$ 3-aminopropyltriethoxysilane (Shin-Etsu Chemical Co.) and stored at $4^{\circ} \mathrm{C}$ until use.

Immunohistochemistry: The detection of antigens was conducted using the indirect method of enzyme immunohistochemistry. Briefly, after rinsing with $0.05 \%$ Tween-added 0.01 M phosphate buffered saline (TPBS; pH
7.4), the sections were immersed in absolute methanol and $0.5 \% \mathrm{H}_{2} \mathrm{O}_{2}$ for $30 \mathrm{~min}$, respectively. Three times TPBS rinse was performed after all preparation steps to remove any reagent residues. Following blocking with $0.06 \%$ normal wild snake serum (prepared in our laboratory) for $1 \mathrm{hr}$ at room temperature (r.t.), the sections were reacted with anti TLR-2 (D-17), -4 (M-16) or -9 (N-15) goat IgG (diluted at 1:100; Santa Cruz Biotechnol., Santa Cruz, CA, U.S.A.) for $18 \mathrm{hr}$ at $6^{\circ} \mathrm{C}$. Antibody specificity for rat TLR-2, -4 or -9 is described in the manufacturer's specification form (TLR-2, sc-12504; TLR-4, sc-12511; TLR-9, sc-13215), respectively. Then, the sections were incubated with horseradish peroxidase-conjugated anti goat IgG mouse IgG (AP186P) (diluted at 1:300; Chemicon International, Billerica, MA, U.S.A.) or horseradish peroxidase-conjugated anti goat IgG donkey IgG (A50-201P) (diluted at 1:200; Bethyl Lab., Montgomery, TX, U.S.A.) for $1 \mathrm{hr}$ at r.t. Finally, the sections were incubated with 3,3'-diaminobenzidine (Dojindo Lab., Mashiki, Japan) containing $0.03 \% \mathrm{H}_{2} \mathrm{O}_{2}$, and were counterstained with hematoxylin. Control sections were incubated with TPBS or non-immunized goat IgG instead of the primary antibody.

Evaluation of immunoreactivity: In at least 5 sections of each immunoreaction with the different primary serum, the reaction intensity was evaluated in consideration with that in the negative control sections. Intensity equal to that in the negative control sections was estimated as "negative", the highest intensities were estimated as "strong", and the intermediate intensity was categorized as "weak".

Histological detection of bacteria: Briefly, after deparaffinization, the sections were stained with Gram's stain reagent solution 1 (Muto Pure Chemicals, Tokyo, Japan) for $2 \mathrm{~min}$ at r.t. After rinsing with distilled water (DW), the sections were incubated with Gram's stain reagent solution 2 (Muto Pure Chemicals) for $1 \mathrm{~min}$ at r.t., followed by rinsing with absolute ethanol for $50 \mathrm{sec}$ and dehydration with acetone for $1 \mathrm{~min}$ at r.t. Following rinsing with DW, the sections were dehydrated with acetone for $1 \mathrm{~min}$ at r.t. As positive controls for Gram's staining, sections of colonies of Bacillus subtilis (Gram-positive bacterium) and E. coli (Gram-negative bacterium) that were cultured on the agar, fixed with 4\% PFA and embedded into paraffin as rat tissues, were stained with Gram's stain kit using the same procedures.

Measurement of Gram-positive and -negative indigenous bacteria: The distributions of Gram-positive and -negative indigenous bacteria were measured using an oil-immersion $100 \times$ objective lens. The intervillous spaces of the ileum were equally divided into the three portions, the apical intervillous portion, middle intervillous portion and basal intervillous portion. Then, 40 samples of each intervillous portion were chosen, and the number of Gram-positive/ negative bacterial colonies was counted in each intervillous portion. The average rates of the number of Gram-positive or -negative bacterial colonies were finally calculated from 5 animals.

Statistical analysis: Data are presented as means \pm standard deviations (S.D.). The Mann-Whitney $U$ test was used to compare the means of the Gram-positive and -negative 
bacterial number in each intervillous space. $P$ values less than 0.05 were considered statistically significant.

\section{RESULTS}

Exocrine glands associated with the upper alimentary tract: In the gustatory gland, all TLRs were weakly positive in some acinar cells, and often in the apical cell membranes of the ductal epithelial cells and luminal substances (Fig. 1a-1f). TLR-2, -4 and -9-positive vesicles were found in the cytoplasm of epithelial cells of a small number of excretory ducts. In the radicular lingual gland, no TLRs were detected in the mucous acinar cells, ductal epithelial cells and luminal substances. In the extraorbital lacrimal gland, all TLRs were strongly detected in almost all acinar cells and apical cell membranes of epithelial cells in the excretory ducts, although all TLRs failed to be detected in the luminal substances (Fig. 2a-2f). Small TLR-2, -4 and -9-positive granules were occasionally found in the cytoplasm of ductal epithelial cells. In the Harderian gland, weakly positive reactions for all TLRs were found in some luminal substances, but only TLR-4 was occasionally found in the acinar cells (Fig. 3a-3d). In the parotid gland, weakly positive reactions for TLR-2 and -9 were occasionally found in the apical membranes and the small vesicles of epithelial cells of the intercalated ducts (Fig. 4a, 4c), but no TLR-4-positive reaction was detected in these ducts, whereas all TLRs failed to be detected in the aninar cells and luminal substances. In the striated ducts, TLR-4 was slightly and occasionally detected in the apical cell membranes and cytoplasmic vesicles of epithelial cells (Fig. 4b), whereas weakly positive reactions for TLR-2 and -9 were often found only in the apical membranes. In the submandibular gland, no TLRs were detected in the acinar cells, ductal epithelial cells and luminal substances. In the sublingual gland, TLR-2 was weakly detected in a small number of mucous acinar cells, and weakly positive reactions for TLR-9 were also often detected in the mucous acinar cells (Fig. 5a, 5c), although TLR-2 and -9 failed to be detected in the luminal substances. No TLR-4 reaction was detected in both of the mucous acinar cells and luminal substances. In the striated ducts, TLR-4-positive vesicles were rarely found in the epithelial cytoplasm (Fig. 5b), but not in the cell membranes, whereas weakly positive reactions for TLR-2 and -9 were occasionally found only in the apical membranes of epithelial cells.

In the proper gastric gland, TLR-2 was weakly detected in the cell membranes of almost all chief cells in the fundus and some luminal substances (Fig. 6a). Weakly positive reactions for TLR-4 and -9 were also rarely found in the secretory granules of chief cells in the body, but failed to be detected in the luminal substances (Fig. 6b, 6c). Secretory granules in the gastric superficial epithelial cells and the luminal substances were negative for TLR-2, -4 and -9 .

Exocrine glands associated with intestine: In the pancreas, positivity for all TLRs was occasionally found in the luminal substances, although all TLRs failed to be detected in the acinar cells (Fig. 7a-7c). In the liver, TLR-2 was not detected in hepatocytes and Kupffer cells. TLR-4-positive vesicles were found in the cytoplasm of hepatocytes and frequently accumulated in front of the sinusoids. TLR-4-positive minute granules were also occasionally found in the perisinusoidal spaces (Fig. 8a); likewise, TLR-4-positive reactions were occasionally found in the cell membranes or cytoplasm of Kupffer cells (Fig. 8b). TLR-9 was homogenously positive in the cytoplasm of a small number of hepatocytes (Fig. 8c). Weakly positive reactions for TLR-9 were often found in the cell membranes or cytoplasm of Kupffer cells. No TLRs were detected in the epithelial cells and the luminal substances of bile ducts. In the duodenal gland, all TLRs were not detected in the acinar cells and luminal substances.

Intestine: In the intestinal crypts, TLR-2 was detected in the striated borders of undifferentiated epithelial cells and luminal substances throughout the small intestine (Fig. 9a). TLR-2-positive reactions were more frequently and strongly detected in the jejunum and ileum than in the duodenum. No immunoreactivity of TLR-2 was detected in Paneth cells and goblet cells. Weakly positive reactions for TLR-4 were found in the striated borders of undifferentiated epithelial cells and the luminal substances throughout the small intestine, but not in any goblet cells throughout the small intestine. TLR-4-positive reactions of undifferentiated epithelial cells were more frequently found in the duodenum than in the jejunum and ileum (Fig. 9b). TLR-4-positive granules were found in the cytoplasm of Paneth cells in the sites with scarce proliferation of indigenous bacteria in the jejunum and ileum, but the reduction of TLR-4-positive granules and the formation of TLR-4-positive vacuoles were found in the cytoplasm of Paneth cells in the ileal sites with hyper-proliferation of indigenous bacteria (Fig. 10a, 10b). However, the relationship between the TLR-4-positivity of the granules of the Paneth cells and indigenous bacteria hyper-proliferation was not determined in the jejunum, because hyper-proliferated indigenous bacteria were hardly found in the jejunum. Weakly positive reactions for TLR9 were found in the striated borders of undifferentiated epithelial cells and luminal substances in a small number of the small intestinal crypts of three animals, but not in the two animals (Fig. 9c). No immunoreactivity of TLR-9 was detected in Paneth cells or goblet cells.

In the intestinal crypts, weakly positive reactions for all TLRs were found in the striated borders of undifferentiated epithelial cells, the secretory granules of goblet cells and luminal substances throughout the large intestine. The TLR-positive goblet cells were fewer in the descending colon and the rectum than in the cecum and the ascending colon (Figs. 11, 12).

The above findings, except for Paneth cells, were not changed in 5 animals, if indigenous bacteriahyper-proliferated on the mucosa. The immunohistochemical results of the secretory glands associated with the rat alimentary tract are summarized in Fig. 13.

Distribution of Gram-positive and -negative indigenous bacteria in the intervillous spaces in the small intestine: In the apical to middle intervillous portions, Gram-positive bacterial colonies were significantly more abundant than Gram-negative bacterial colonies $(P<0.05)$, whereas this 

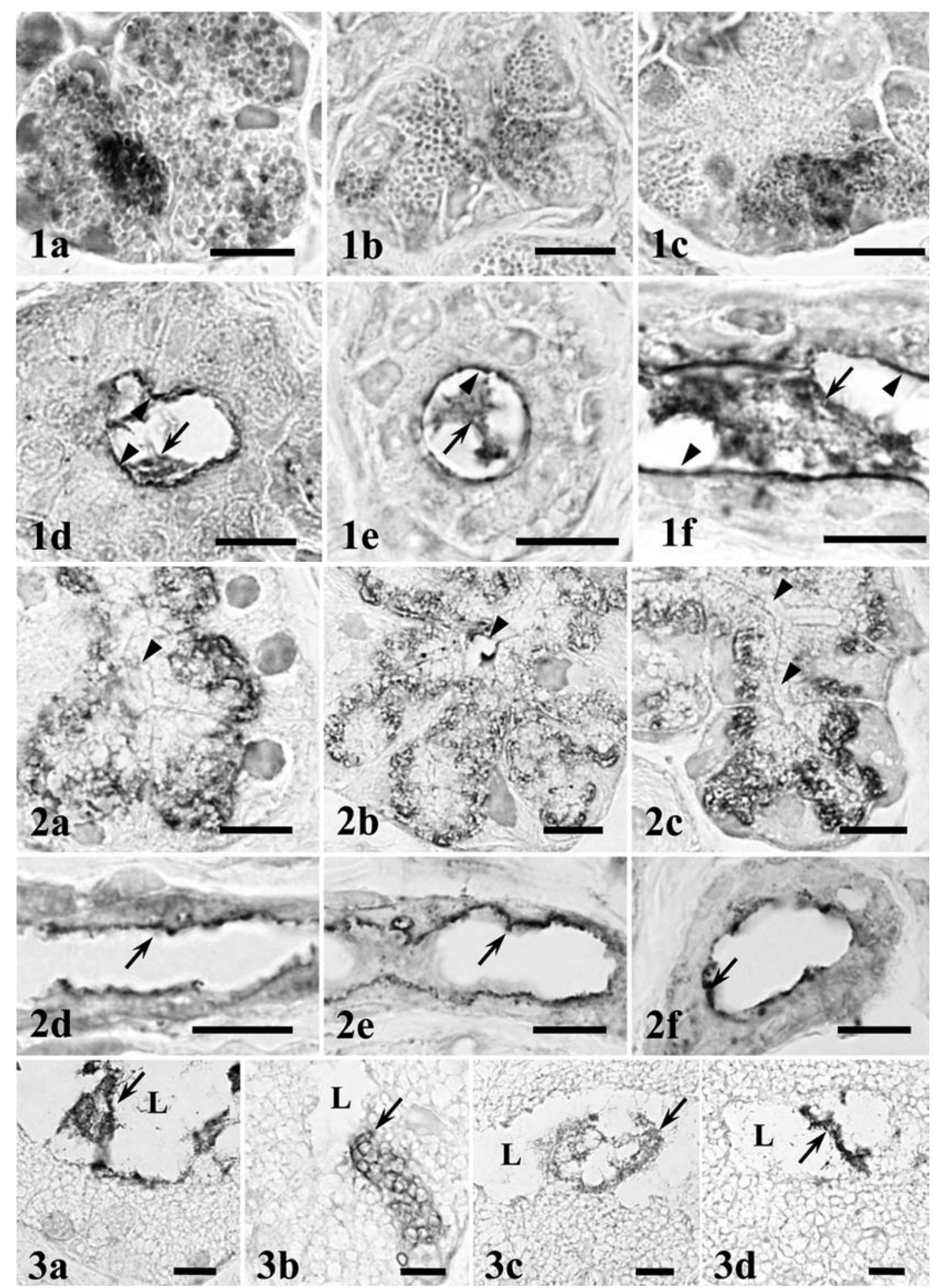

Fig. 1. The localization of TLR-2 (a, d), -4 (b, e) and -9 (c, f) in the gustatory gland. TLR-2, -4 and -9-positive reactions are visible in acinar cells (a-c), apical cell membranes of ductal epithelial cells (d-f, arrowheads) and luminal substances (d-f, arrows). Bar=10 $\mu \mathrm{m}$.

Fig. 2. The localization of TLR-2 (a, d), -4 (b, e) and -9 (c, f) in the extraorbital lacrimal gland. TLR-2, -4 and -9-positive reactions are visible in acinar cells (a-c) and apical cell membranes of ductal epithelial cells (d-f, arrows). Arrowheads, Lumen. Bar $=10 \mu \mathrm{m}$.

Fig. 3. The localization of TLR-2 (a), -4 (b, c) and -9 (d) in Harderian gland. Luminal substances are positive for TLR-2 and -9 (a, d, arrows). TLR-4-positive reaction is visible in an acinar cell (b, arrow) and luminal substance (c, arrow). L, Lumen. Bar $=10 \mu \mathrm{m}$. 


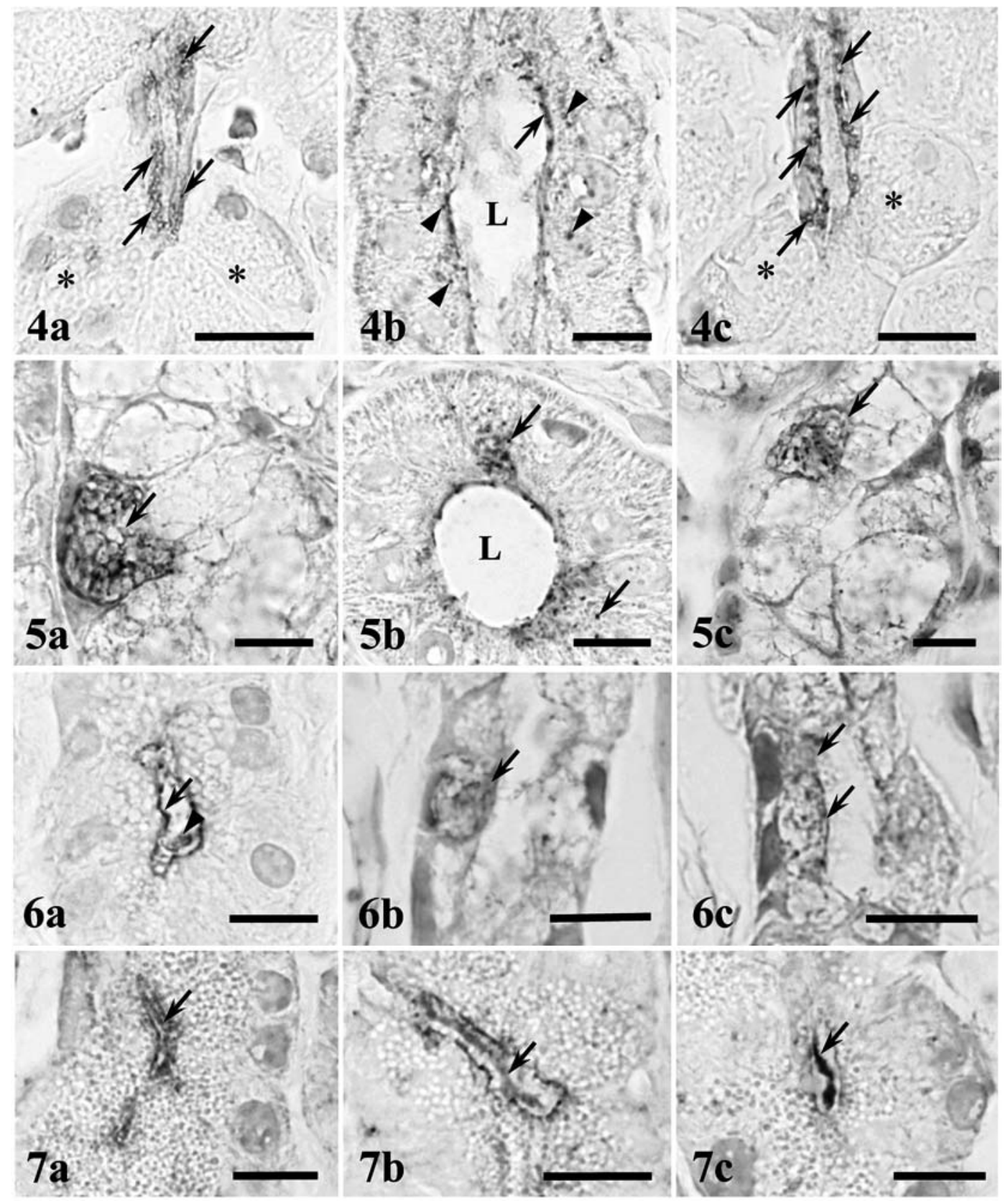

Fig. 4. The localization of TLR-2 (a), -4 (b) and -9 (c) in the parotid gland. Vesicles positive for TLR-2 and -9 (a, c, arrows) are visible in the epithelial cells of intercalated ducts, but not in the acinar cells (asterisks). In the striated duct, TLR-4-positive vesicles are seen in the cytoplasm (arrowheads), and the apical membranes of epithelial cells are also positive for TLR-4 (b, arrow). L, Lumen. Bar $=10 \mu \mathrm{m}$.

Fig. 5. The localization of TLR-2 (a), -4 (b) and -9 (c) in the sublingual gland. Weakly TLR-2 and -9-positive reactions are visible in a mucous acinar cell (a, c, arrows). TLR-4-positive vesicles are seen in the epithelial cytoplasm of the striated duct (b, arrows). L, Lumen. Bar=10 $\mu \mathrm{m}$.

Fig. 6. The localization of TLR-2 (a), -4 (b) and -9 (c) in the proper gastric gland. TLR-2-positive reaction is visible in the apical cell membranes of chief cells in the fundus (a, arrow) and luminal substance (a, arrowhead). TLR-4 and -9-positive reactions are visible in the secretory granules of chief cells in the body (b, c, arrows). Bar=10 $\mu \mathrm{m}$.

Fig. 7. Luminal substances are positive for TLR-2 (a), -4 (b) and -9 (c) in the pancreas (arrows). Bar=10 $\mu \mathrm{m}$. 


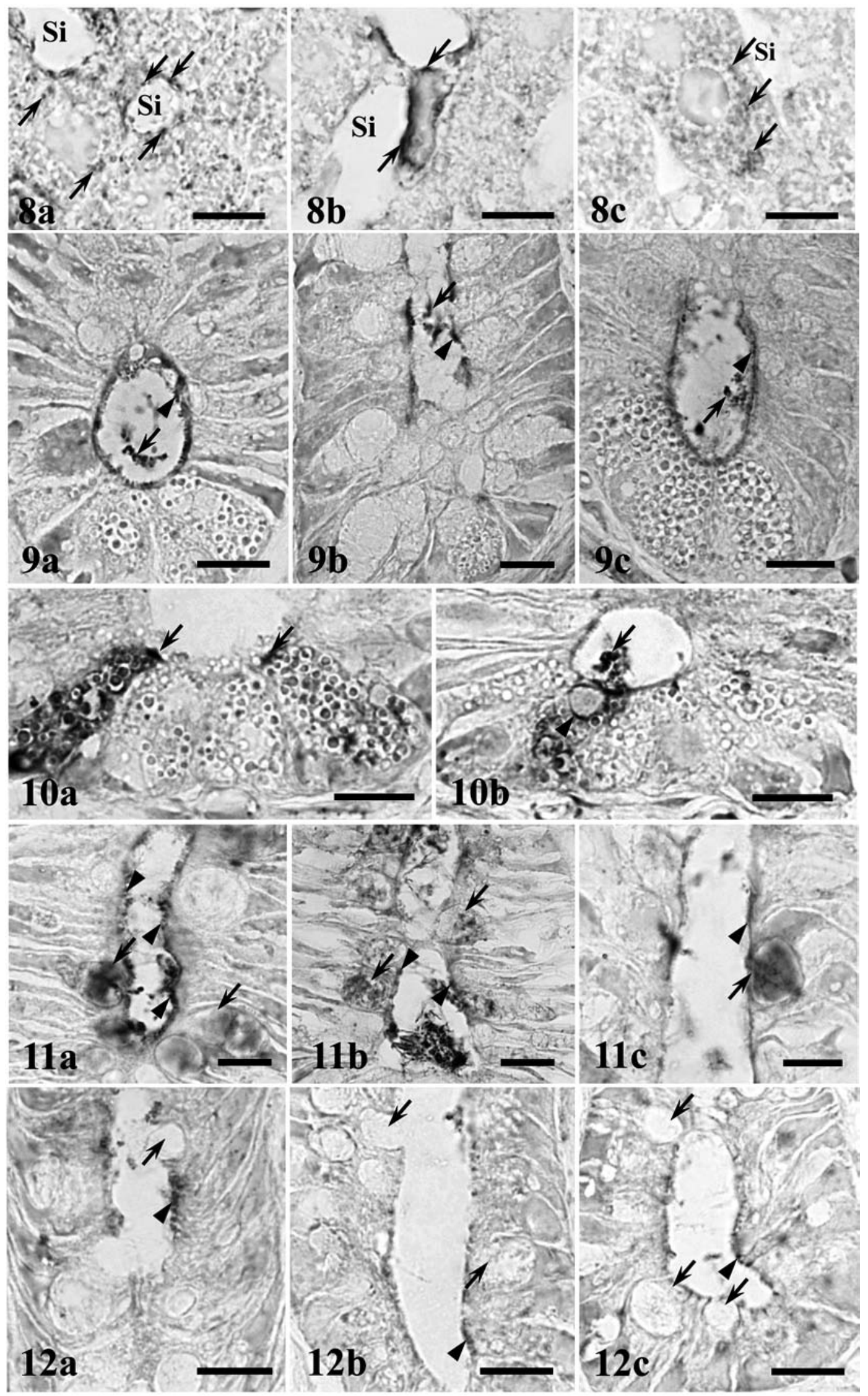




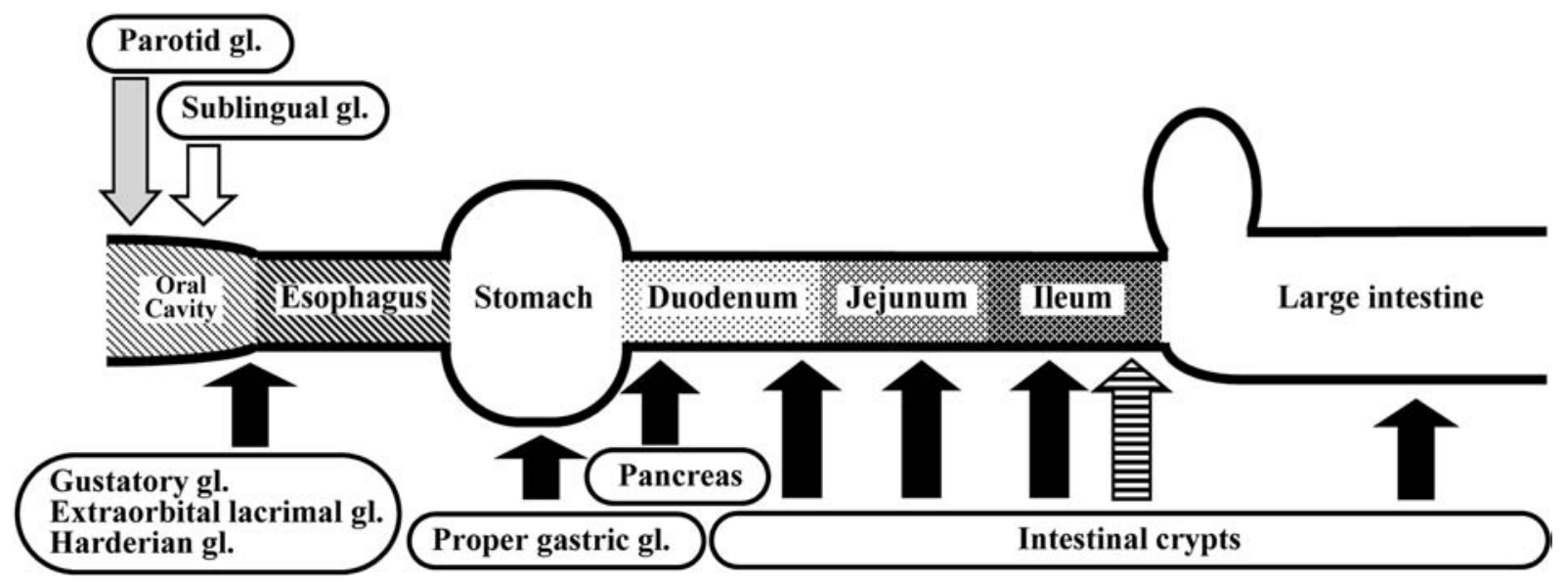

Fig. 13. A schema of possible TLR-secretion sites in rat alimentary organ. Black arrows, positive for all TLRs in the secretory materials; gray arrow, negative for all TLRs in the secretory materials but positive in the other glandular components; white arrow, positive for TLR-2 and -9 in the secretory materials but positive for TLR-4 in the other glandular components; striped arrows, transient secretion of TLR-4 from Paneth cells only under the hyper-proliferation of indigenous bacteria.

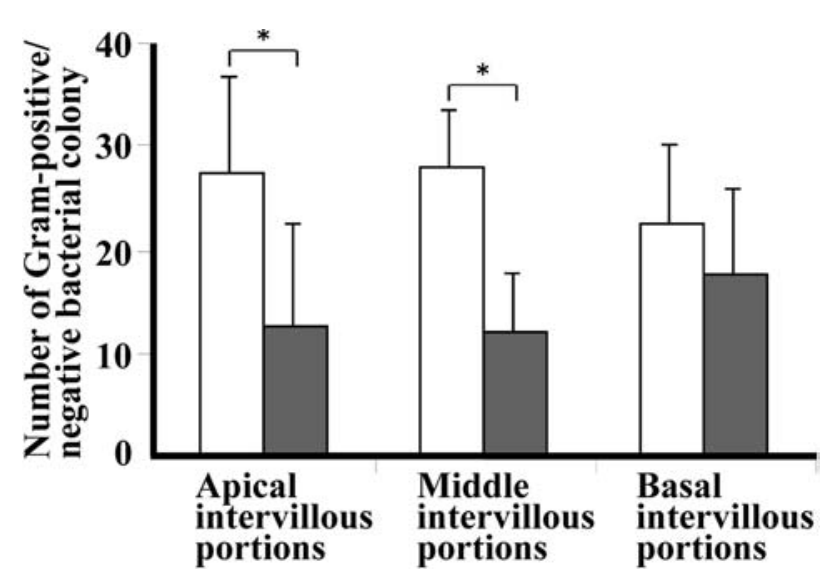

Fig. 14. Appearance frequencies of Gram-positive (white column) and -negative bacterial colonies (gray column) in the intervillous spaces of the rat ileum. Asterisks, $P<0.05$. Each value represents mean \pm S.D. difference disappeared in the basal intervillous portions, because the appearance of Gram-negative bacteria was frequent there (Fig. 14).

\section{DISCUSSION}

sTLRs are detected in the salivary fluid with the western blotting method [24, 45], whereas the existence of sTLRs in other digestive fluids and TLR-secretory sources have not been clarified. In the present study, TLR-2, -4 and -9 were detected in the gustatory gland associated with the upper alimentary tract, and TLR-2 and -9 were detected in the sublingual gland. All TLRs were detected in the extraorbital lacrimal gland and Harderian gland, whose secretions eventually flow into the upper alimentary tract. sTLRs were also detected in the proper gastric gland, pancreas and intestinal crypts throughout the intestine. However, sTLRs were not detected in the submandibular gland, radicular lingual gland and liver. These findings suggest that there are distributional differences in the secretory sources of sTLRs

Fig. 8. The localization of TLR-4 (a, b) and -9 (c) in the liver. TLR-4-positive vesicles are visible in the cytoplasm of hepatocytes (a, arrows), and TLR-4-positive reaction is visible in the cell membranes of Kupffer cells in the sinusoid (b, arrows). Homogenous TLR-9-positive reaction is visible in the cytoplasm of hepatocytes (c, arrows). Si, Sinusoid. Bar $=10 \mu \mathrm{m}$.

Fig. 9. The localization of TLR-2 (a), -4 (b) and -9 (c) in the small intestinal crypts. Weakly TLR-2 and -9-positive reaction is visible in the striated borders of undifferentiated epithelial cells (arrowhead) and luminal substance (arrow) in the ileal crypt (a, c). Weakly TLR-4-positive reaction is also visible in the striated borders of undifferentiated epithelial cells (arrowhead) and luminal substance (arrow) in the duodenal crypt (b). Bar=10 $\mu \mathrm{m}$.

Fig. 10. The localization of TLR-4 in Paneth cells of the ileal crypts. Many TLR-4-positive granules are visible in Paneth cells in the sites with scarce proliferation of indigenous bacteria (a, arrows); in the sites with hyper-proliferation of indigenous bacteria, the reduction of TLR-4-positive granules and the formation of TLR-4-positive vacuoles (arrowhead) are visible in Paneth cells and TLR-4-positive reaction is also visible in luminal substances (b, arrow). Bar $=10 \mu \mathrm{m}$.

Fig. 11. The localization of TLR-2 (a), -4 (b) and -9 (c) in the cecal crypts. Weak immuno-positivity for all TLRs is visible in the striated borders of undifferentiated epithelial cells (arrowheads), and the secretory granules of goblet cells (arrows). Bar=10 $\mu \mathrm{m}$.

Fig. 12. The localization of TLR-2 (a), -4 (b) and -9 (c) in the intestinal crypt of the descending colon. Weak positivity for all TLRs is visible in the striated borders of undifferentiated epithelial cells (arrowheads), but not in the goblet cells (arrows). Bar=10 $\mu \mathrm{m}$. 
throughout the alimentary tract.

The oral cavity contains over 200 species of indigenous bacteria. Saliva contains $10^{6} / \mathrm{ml}$ of transient bacteria shed from oral surfaces such as the tongue and the cheek [17]. On the one hand, the various bactericidal peptides, such as lysozyme, sPLA2, and $\beta$-defensin- 1 and -2 , are contained in the salivary fluid, lacrimal fluid and gastric juice [41]. Lysozyme hydrolyses the $\beta-(1,4)$-glycosidic bond between the alternating $\mathrm{N}$-acetylmuramic acid and $\mathrm{N}$-acetylglucosamine residues of peptidoglycan, which are TLR-2 ligands $[8,11]$. Defensins act by forming pores in microbial cell membranes that depolarize and kill microbes [28]. sPLA2 acts by degrading ester bonds in the phospholipid layer of bacteria [29]. Thus, the bactericidal substances are considered to contribute the constant release of the TLR ligands from the bacteria into the alimentary tract. On the other hand, TLR-2, -4 and -9 are expressed in the striated borders of the villous columnar epithelial cells in the rat duodenum, where the luminal contents of the upper alimentary tract are initially received [26]. Furthermore, Kuroishi et al. [24] hypothesized that sTLRs in salivary fluid neutralize the luminal ligands. The present study suggests that sTLRs are secreted by excretory glands associated with rat upper and middle alimentary tracts. Therefore, the sTLRs probably neutralize certain quantities of their ligands from the upper alimentary tract to modulate the threshold amount of indigenous bacteria recognized by membranous TLRs on the duodenal villous columnar epithelial cells.

In the rat small intestine, the fundamental settlement sites of indigenous bacteria are the apical portions of the intestinal villi. From these settlement sites, the indigenous bacterial colonies expand into the intervillous spaces [38]. Host defenses, such as the acceleration of cell migrations, are precisely induced depending on the degree of expansion of the bacterial colonies in the intervillous spaces [31]. Bacterial proliferation might be detected by membranous TLR-2 expressed in the villous columnar epithelial cells throughout the rat small intestine [26]. TLR-2 recognizes both Gram-positive and -negative bacteria [37], because TLR-2 ligands such as peptidoglycan are contained in both. On the other hand, lysozyme and sPLA2 are transiently secreted from Paneth cells in the mucosa where indigenous bacteria hyper-proliferate into deeper intervillous spaces $[40,41]$. Therefore, a large amount of TLR-2 ligands are probably released from hyper-proliferated indigenous bacteria by the action of lysozyme in the intervillous spaces. In the present study, TLR-2 was constantly detected in the luminal substances of the small intestinal crypts. From these findings, we can deduce that sTLR-2 is secreted from the intestinal crypts, probably to neutralize TLR-2 ligands released from bacteria in the intervillous spaces. The neutralization of the ligands by sTLR-2 probably prevents the excess host defense response that would be caused by exposure of membranous TLR to an overabundance of ligands in the intervillous spaces of small intestine.

Gram-positive bacteria are significantly more abundant than Gram-negative bacteria in the upper alimentary tract and decrease toward the caudal alimentary tract, whereas
Gram-negative bacteria are significantly more abundant than Gram-positive bacteria in the large intestine. In the small intestine, the predominance of Gram-positive bacteria is irregularly changed to a predominance of Gram-negative bacteria [40]. Yokoo et al. [40] hypothesize that this change of the predominance of Gram-positive bacteria might be caused by the transient secretion of lysozymes and sPLA2 from Paneth cells under hyper-proliferation of indigenous bacteria. Peptidoglycan in the bacterial cell wall is thicker in Gram-positive bacteria than in Gram-negative bacteria, and lies on the surface of Gram-positive bacteria, but on the inside of the outer membrane of Gram-negative bacteria [7]. Thus, peptidoglycan, a TLR-2 ligand, is considered to be more easily released from Gram-positive bacteria than Gram-negative bacteria in the presence of lysozymes, which implies the preferential recognition of Gram positive bacteria by TLR-2-positive villous columnar epithelial cells. The present study found that Gram-positive bacteria were abundant in the apical intervillous spaces, whereas Gram-negative bacteria were abundant in the basal intervillous spaces. These findings support the hypothesis of Yokoo et al. [40] and suggest that Gram-positive bacteria are excluded more easily than Gram-negative bacteria from the intervillous spaces by the host defense mechanism based on the TLR-2 recognition system of the villous columnar epithelial cells in the rat ileum.

In the present study, the secretory granules of Paneth cells were immunopositive for TLR-4. Furthermore, the TLR-4-positive granules were reduced and TLR-4-positive vacuoles increased in Paneth cells in the mucosa with hyper-proliferation of indigenous bacteria. Vacuole formation is considered to result from the massive release of secretory granules and to be involved in the recycling of the granule membranes in Paneth cells [33]. From these findings, sTLR-4 is suggested to be secreted with lysozyme and sPLA2 from Paneth cells in response to the hyper-proliferation of indigenous bacteria. Luminal LPS, which is a ligand for TLR-4, induces various kinds of intestinal inflammation, such as colitis and diarrhea [18, 27], but sTLR-4 neutralizes LPS and prevents LPS recognition by membranous TLR-4 [21, 45]. However, membranous TLR-4 is not expressed in the villous columnar epithelial cells in the rat ileum [26]. On the other hand, the localization of membranous TLR-4 in the rat large intestine is not clarified, although mRNA of TLR-4 can be detected in the next intestinal segment, cecum with the RT-PCR method [36]. Taken together, sTLR-4 secretion by Paneth cells in response to hyper-proliferation of indigenous bacteria in the ileum might contribute to a neutralization of luminal LPS in the large intestine. However, the localization of membranous TLR-4 in the rat large intestine has not been clarified. In addition, TLR-2 is also involved in LPS recognition in the presence of co-receptors, such as CD-14 and MD-2 [13]. On these points, our investigation is progressing to clarify the LPS-recognition systems throughout the rat large intestine.

In general, intestinal epithelial cells absorb various exogenous substances, such as food-derived nutrients and bacteria-derived substances, such as LPS [12, 15, 22]. 
Recently, many investigators have reported the phenomenon called persorption, by which the villous columnar epithelial cells absorb macromolecules or particulates, which are transported into the hepatic portal vein without any digestion [23, 35, 42, 43]. Our previous immunohistochemical study clarified that TLR-4-positive minute granules, possibly sTLR-4-LPS complexes, are persorbed from the intestinal lumen into the hepatic portal vein by the villous columnar epithelial cells [26]. The liver has an important role for the clearance of blood LPS in mice [44], canines [9] and humans [22]. In the present study, TLR-4-positive vesicles were detected in the hepatocytes and the perisinusoidal spaces, and TLR-4-positive reactions were also found in Kupffer cells. Furthermore, no TLR-4-positive reaction was detected in the bile ducts. From these findings, the hepatocytes and Kupffer cells might catabolize the TLR-4-positive-aggregations, possibly TLR-4-LPS complexes, derived from the intestinal lumen.

ACKNOWLEDGMENT. This work was financially supported in part by a Grant-in-Aid for Scientific Research (nos. 23580403 and 24-2965) from the Japan Society for the Promotion of Science.

\section{REFERENCES}

1. Akira, S., Uematsu, S. and Takeuchi, O. 2006. Pathogen recognition and innate immunity. Cell 124: 783-801. [Medline] [CrossRef]

2. Barthel, L. K. and Raymond, P. A. 1990. Improved method for obtaining 3- $\mu \mathrm{m}$ cryosections for immunocytochemistry. $J$. Histochem. Cytochem. 38: 1383-1388. [Medline] [CrossRef]

3. Batt, R. M., Rutgers, H. C. and Sancak, A. A. 1996. Enteric bacteria: friend or foe? J. Small Anim. Pract. 37: 261-267. [Medline] [CrossRef]

4. Berg, R. D. 1996. The indigenous gastrointestinal microflora. Trends Microbiol. 4: 430-435. [Medline] [CrossRef]

5. Blais, D. R., Vascotto, S. G., Griffith, M. and Altosaar, I. 2005. LBP and CD14 secreted in tears by the lacrimal glands modulate the LPS response of corneal epithelial cells. Invest. Ophthalmol. Vis. Sci. 46: 4235-4244. [Medline] [CrossRef]

6. Bourlioux, P., Koletzko, B., Guarner, F. and Braesco, V. 2003. The intestine and its microflora are partners for the protection of the host: report on the Danone Symposium "the intelligent intestine,” held in Paris, June 14, 2002. Am. J. Clin. Nutr. 78: 675-683. [Medline]

7. Cabeen, M. T. and Jacobs-Wagner, C. 2005. Bacterial cell shape. Nat. Rev. Microbiol. 3: 601-610. [Medline] [CrossRef]

8. Callewaert, L. and Michiels, C. W. 2010. Lysozymes in the animal kingdom. J. Biosci. 35: 127-160. [Medline] [CrossRef]

9. Caruana, J. A., Camara, D. S., Schneeberger, G. J. and Nolan, J. P. 1984. The clearance capacity of the canine liver for a portal vein endotoxin infusion. J. Surg. Res. 37: 197-201. [Medline] [CrossRef]

10. Chin, K., Onishi, S., Yuji, M., Inamoto, T., Qi, W.M., Yamamoto, K., Warita, K., Yokoyama, T., Hoshi, N. and Kitagawa, H. 2007. Special sugar expression on apoptotic epithelial cells of Peyer's patches and intestinal villi in rat small intestine. J. Vet. Med. Sci. 69: 193-199. [Medline] [CrossRef]

11. Cole, A. M. and Ganz, T. 2005. Defensins and other antimicrobial peptides: innate defense of mucosal surfaces. pp 17-34. In:
Colonization of Mucosal Surfaces, 2nd ed. (James, P. N. et al. eds.), ASM Press, Washington, D. C.

12. Drewe, J., Beglinger, C. and Fricker, G. 2001. Effect of ischemia on intestinal permeability of lipopolysaccharides. Eur. J. Clin. Invest. 31: 138-144. [Medline] [CrossRef]

13. Driarski, R., Wang, Q., Miyake, K., Kirschning, C. J. and Gupta, D. 2001. MD-2 enables Toll-like receptor 2 (TLR2)-mediated responses to lipopolysaccharide and enhances TLR2-mediated responses to Gram-positive and Gram-negative bacteria and their cell wall components. J. Immunol. 166: 1938-1944. [Medline]

14. Fazeli, A., Bruce, C. and Anumba, D. O. 2005. Characterization of Toll-like receptors in the female reproductive tract in humans. Hum. Reprod. 20: 1372-1378. [Medline] [CrossRef]

15. Ghoshal, S., Witta, J., Zhong, J., de Villiers, W. and Eckhardt, E. 2009. Chylomicrons promote intestinal absorption of lipopolysaccharides. J. Lipid Res. 50: 90-97. [Medline] [CrossRef]

16. Gleeson, M., McFarlin, B. and Flynn, M. 2006. Exercise and Toll-like receptors. Exerc. Immunol. Rev. 12: 34-53. [Medline]

17. Hardie, J. M. and Bowden, G. H. 1974. The normal microbial flora of the mouth. Soc. Appl. Bacteriol. Symp. Ser. 3: 47-83. [Medline]

18. Hotta, T., Yoshida, N., Yoshikawa, T., Sugino, S. and Kondo, M. 1986. Lipopolysaccharide-induced colitis in rabbits. Res. Exp. Med. (Berl.) 186: 61-69. [Medline] [CrossRef]

19. Inamoto, T., Kawata, Y., Qi, W.M., Yamamoto, K., Warita, K., Kawano, J., Yokoyama, T., Hoshi, N. and Kitagawa, H. 2008. Ultrastructural study on the epithelial responses against attachment of indigenous bacteria to epithelial membranes in Peyer's patches of rat small intestine. J. Vet. Med. Sci. 70: 235-241. [Medline] [CrossRef]

20. Inamoto, T., Namba, M., Qi, W.M., Yamamoto, K., Yokoo, Y., Miyata, H., Kawano, J., Yokoyama, T., Hoshi, N. and Kitagawa, H. 2008. An immunohistochemical detection of actin and myosin in the indigenous bacteria-adhering sites of microvillous columnar epithelial cells in Peyer's patches and intestinal villi in the rat jejunoileum. J. Vet. Med. Sci. 70: 1153-1158. [Medline] [CrossRef]

21. Iwami, K. I., Matsunaga, T., Masuda, A., Kikuchi, T., Musikacharoen, T. and Yoshikai, Y. 2000. Cutting edge: naturally occurring soluble form of mouse Toll-like receptor 4 inhibits lipopolysaccharide signaling. J. Immunol. 165: 6682-6686. [Medline]

22. Jacob, A. I., Goldberg, P. K., Bloom, N., Degenshein, G. A. and Kozinn, P. J. 1977. Endotoxin and bacteria in portal blood. Gastroenterology 72: 1268-1270. [Medline]

23. Kitagawa, H., Yoshizawa, Y., Yokoyama, T., Takeuchi, T., Talukder, M. J. R., Shimizu, H., Ando, K. and Harada, E. 2003. Persorption of bovine lactoferrin from the intestinal lumen into the systemic circulation via the portal vein and the mesenteric lymphatics in growing pigs. J. Vet. Med. Sci. 65: 567-572. [Medline] [CrossRef]

24. Kuroishi, T., Tanaka, Y., Sakai, A., Sugawara, Y., Komine, K. and Sugawara, S. 2007. Human parotid saliva contains soluble Toll-like receptor (TLR) 2 and modulates TLR2-mediated interleukin-8 production by monocytic cells. Mol. Immunol. 44: 1969-1976. [Medline] [CrossRef]

25. LeBouder, E., Rey-Nores, J. E., Rushmere, N. K., Grigorov, M., Lawn, S. D., Affolter, M., Griffin, G. E., Ferrara, P., Schiffrin, E. J., Morgan, B. P. and Labéta, M. O. 2003. Soluble forms of Tolllike receptor (TLR) 2 capable of modulating TLR2 signaling are present in human plasma and breast milk. J. Immunol. 171: 6680-6689. [Medline] 
26. Mantani, Y., Kamezaki, A., Udayanga, K. G. S., Takahara, E., Qi, W.M., Kawano, J., Yokoyama, T., Hoshi, N. and Kitagawa, H. 2011. Site differences of Toll-like receptor expression in the mucous epithelium of rat small intestine. Histol. Histopathol. 26: 1295-1303. [Medline]

27. Mathan, V. I., Penny, G. R., Manthan, M. M. and Rowley, D. 1988. Bacterial lipopolysaccharide-induced intestinal microvascular lesions leading to acute diarrhea. J. Clin. Invest. 82: 1714-1721. [Medline] [CrossRef]

28. Mathews, M., Jia, H. P., Guthmiller, J. M., Losh, G., Graham, S., Johnson, G. K., Tack, B. F. and McCray, P. B. Jr. 1999. Production of $\beta$-defensin antimicrobial peptides by the oral mucosa and salivary glands. Infect. Immun. 67: 2740-2745. [Medline]

29. Menschikowski, M., Hagelgans, A. and Siegert, G. 2006. Secretory phospholipase A2 of group IIA: Is it an offensive or a defensive player during atherosclerosis and other inflammatory diseases? Prostaglandins Other Lipid Mediat. 79: 1-33. [Medline] [CrossRef]

30. Netea, M. G., Van der Meer, J. W. M. and Kullberg, B. J. 2006. Recognition of pathogenic microorganisms by Toll-like receptors. Drugs Today (Barc) 42: 99-105. [Medline]

31. Qi, W.M., Yamamoto, K., Yokoo, Y., Miyata, H., Inamoto, T., Udayanga, K. G. S., Kawano, J., Yokoyama, T., Hoshi, N. and Kitagawa, H. 2009. Histoplanimetrical study on the relationship between the cell kinetics of villous columnar epithelial cells and the proliferation of indigenous bacteria in rat small intestine. $J$. Vet. Med. Sci. 71: 463-470. [Medline] [CrossRef]

32. Salminen, S., Isolauri, E. and Onnela, T. 1995. Gut flora in normal and disordered states. Chemotherapy 41: 5-15. [Medline] [CrossRef]

33. Satoh, Y. and Vollrath, L. 1986. Quantitative electron microscopic observations on Paneth cells of germfree and ex-germfree Wistar rats. Anat. Embryol. (Berl.) 173: 317-322. [Medline] [CrossRef]

34. Srinivasan, M., Kodumudi, K. N. and Zunt, S. L. 2008. Soluble CD14 and Toll-like receptor-2 are potential salivary biomarkers for oral lichen planus and burning mouse syndrome. Clin. Immunol. 126: 31-37. [Medline] [CrossRef]

35. Takeuchi, T., Kitagawa, H. and Harada, E. 2004. Evidence of lactoferrin transportation into blood circulation from intestine via lymphatic pathway in adult rats. Exp. Physiol. 89: 263-270. [Medline] [CrossRef]

36. Terán-Ventura, E., Roca, M., Martin, M. T., Abarca, M. L., Martinez, V. and Vergara, Patri. 2010. Characterization of houserelated spontaneous variations of gut microbiota and expression of Toll-like receptors 2 and 4 in rats. Microb. Ecol. 60: 691-702. [Medline] [CrossRef]

37. Tietze, K., Dalpke, A., Morath, S., Mutters, R., Heeg, K. and Nonnenmacher, C. 2006. Differences in innate immune responses upon stimulation with Gram-positive and Gramnegative bacteria. J. Periodontal Res. 41: 447-454. [Medline] [CrossRef]

38. Yamamoto, K., Qi, W.M., Yokoo, Y., Miyata, H., Udayanga, K. G. S., Kawano, J., Yokoyama, T., Hoshi, N. and Kitagawa, H. 2009. Histoplanimetrical study on the spatial relationship of distribution of indigenous bacteria with mucosal lymphatic follicles in alimentary tract of rat. J. Vet. Med. Sci. 71: 621-630. [Medline] [CrossRef]

39. Yamamoto, K., Qi, W.M., Yokoo, Y., Miyata, H., Udayanga, K. G. S., Kawano, J., Yokoyama, T., Hoshi, N. and Kitagawa, H. 2010. Lectin histochemical detection of special sugars on the mucosal surfaces of the rat alimentary tract. J. Vet. Med. Sci. 72: 1119-1127. [Medline] [CrossRef]

40. Yokoo, Y., Miyata, H., Udayanga, K. G. S., Qi, W.M., Takahara, T., Mantani, Y., Yokoyama, T., Kawano, J., Hoshi, N. and Kitagawa, H. 2011. Immunohistochemical and histoplanimetrical study on the spatial relationship between the settlement of indigenous bacteria and the secretion of bactericidal peptides in rat alimentary tract. J. Vet. Med. Sci. 73: 1043-1050. [Medline] [CrossRef]

41. Yokoo, Y., Miyata, H., Udayanga, K. G. S., Qi, W.M., Takahara, T., Yokoyama, T., Kawano, J., Hoshi, N. and Kitagawa, H. 2011. Immunohistochemical study on the secretory host defense system of bactericidal peptides in rat digestive organs. J. Vet. Med. Sci. 73: 217-225. [Medline] [CrossRef]

42. Yuji, M., Fujimoto, M., Miyata, H., Inamoto, T., Qi, W.M., Yamamoto, K., Warita, K., Yokoyama, T., Hoshi, N. and Kitagawa, H. 2007. Persorption mechanisms of luminal antigenic particulates via apoptotic epithelial cells of intestinal villi into systemic blood circulation in orally immunized rats. $J$. Vet. Med. Sci. 69: 339-346. [Medline] [CrossRef]

43. Yuji, M., Tsubata, M., Chin, K., Onishi, S., Inamoto, T., Qi, W.M., Warita, K., Yokoyama, T., Hoshi, N. and Kitagawa, H. 2006. Persorption of luminal antigenic molecule and its specific antibody via apoptotic epithelial cells of intestinal villi and Peyer's patches into peripheral blood in rats. J. Vet. Med. Sci. 68: 1297-1305. [Medline] [CrossRef]

44. Zlydaszyk, J. C. and Moon, R. J. 1976. Fate of ${ }^{51} \mathrm{Cr}$-labeled lipopolysaccharide in tissue culture cells and livers of normal mice. Infect. Immun. 14: 100-105. [Medline]

45. Zunt, S. L., Burton, L. V., Goldblatt, L. I., Dobbins, E. E. and Srinivasan, M. 2009. Soluble forms of Toll-like receptor 4 are present in human saliva and modulate tumour necrosis factor- $\alpha$ secretion by macrophage-like cells. Clin. Exp. Immunol. 156: 285-293. [Medline] [CrossRef] 